\title{
GÊNERO: \\ REPRESENTAÇÕES DE \\ ALUNOS DO ENSINO FUNDAMENTAL
}

GENDER: REPRESENTATIONS OF ELEMENTARY SCHOOL STUDENTS GÉNERO: REPRESENTACIONES DE ALUMNOS DE LA ENSEÑANZA FUNDAMENTAL

Fabio Luiz da Silva'

Cyntia Simioni França²

'Doutor em História pela UNESP. Docente no Mestrado em Metodologias para o Ensino de Linguagens e suas Tecnologias da Universidade Norte do Paraná (UNOPAR) - Londrina - PR - Brasil.

${ }^{2}$ Doutora em Educação pela UNICAMP. Docente na Universidade Norte do Paraná (UNOPAR) - Londrina - PR - Brasil.

Resumo: Esse artigo objetiva descrever os resultados de uma pesquisa que investigou as representações de gênero entre alunos de escola pública, dos anos iniciais do ensino fundamental II. $O$ estudo foi realizado em seis turmas do sexto ano do ensino fundamental, totalizando 226 alunos, dos quais 126 meninos e 100 meninas, entre 10 e 11 anos. Foi solicitado que as crianças expressassem por meio da escrita e do desenho sua opinião a respeito do que é "ser homem" e "ser mulher". O objetivo era descobrir as representações que esses alunos tinham em relação à questão do gênero. Flagraram-se nessa atividade algumas imagens (desenhos) que trazem as vozes dos alunos acerca do que é "ser homem e o que 
é ser mulher" na contemporaneidade, carregadas de visões estereotipadas. A partir dos desenhos dos alunos pôde-se pensar sobre os desafios e as potencialidades de se discutir as relações entre diversidade e gênero no espaço escolar, a fim de buscar propostas de ação docente mais efetivas, no sentido de construir outro olhar para a diversidade e alterações das relações de gênero na escola e, portanto, na sociedade. Tarefa, certamente, árdua, mas possível e emergente, pois a desigualdade de gênero implica relações assimétricas de poder.

Palavras-chave: Gênero; imagens; escola.

Abstract: This article describes the results of a study to investigate gender representations among public school students in the initial years of elementary school II. The study was conducted in six classes of the sixth grade of elementary school, totaling 226 students, including 126 boys and 100 girls aged between 10 and 11 years. The children were asked to express, through written text and drawings, their opinions about what it means to "be a man" and to "be a woman". The aim was to discover the representations held by these students in relation to gender issues. In this activity, some pictures (drawings) are seen that show the students' perspectives of what it means to "be a man and to be a woman" in the contemporary world, full of stereotyped views. Based on the students' drawings, we can think about the challenges, and the opportunities to discuss the relationships between diversity and gender at school, in order to search for more effective proposals for teaching action, and build another look at diversity and changes in gender relationships in school, and thus, in society. This is certainly a difficult task, but a possible and emerging one, as gender inequality implies asymmetrical power relations. 
Keywords: Gender; images; school.

Resumen: Este artículo objetiva describir los resultados de un estudio que investigó las representaciones de género entre alumnos de la escuela pública en los años iniciales de la enseñanza fundamental II. El estudio fue realizado en seis clases del sexto año de la enseñanza fundamental, totalizando 226 alumnos, de los cuales 126 niños y 100 niñas de 10 y 11 años. Se solicitó que los niños expresaran a través de la escritura y del dibujo su opinión a respeto de lo que sería "ser hombre" y "ser mujer". El objetivo era descubrir las representaciones que esos alumnos tenían en relación a la cuestión de género. Sorprendimos en esa actividad algunas imágenes (dibujos) que traen las voces de los alumnos acerca de "lo que es ser hombre y lo que es ser mujer" en la contemporaneidad, cargadas de visiones estereotipadas. A partir de los dibujos de los alumnos se pudo pensar sobre los desafíos y potencialidades de discutir las relaciones entre diversidad y género en el espacio escolar a fin de buscar propuestas de acción docente más efectivas, en el sentido de construir otra mirada hacia la diversidad y alteraciones de las relaciones de género en la escuela $y$, por lo tanto, en la sociedad. Es una tarea seguramente ardua, pero posible y emergente, pues la desigualdad de género implica relaciones asimétricas de poder.

Palabras clave: Género; Imágenes; Escuela.

\section{INTRODUÇÃO}

acilmente encontram-se inúmeros exemplos históricos da desigual relação entre homens e mulheres. Em um jornal de 1875, um médico referia-se às mulheres afirmando que o sistema nervoso delas seria 
mais delicado e que, por isso, elas possuiriam as virtudes da doçura, da indulgência e da submissão (RIBEIRO, 1996). No artigo 25 do decreto Lei 4.244 de 1942, que trata da organização do ensino no Brasil, consta a seguinte determinação: "A orientação metodológica dos programas terá em mira a natureza da personalidade feminina e bem assim a missão da mulher dentro do lar" (BRASIL, 1942, s/p). A naturalização da desigualdade de gênero é explícita nesses dois exemplos e contribui para demonstrar a importância da temática de gênero no esforço de compreensão da sociedade como um todo e da escola em particular.

Para Hobsbawm (1995), após o final da Segunda Guerra Mundial, houve um aumento considerável de mulheres casadas no mercado de trabalho e nas universidades. Isto, segundo ele, explicaria o reflorescimento dos movimentos feministas a partir da década de 1960, que contribuíram para uma revolução cultural caracterizada pelas mudanças na estrutura da família tradicional e nas atividades domésticas, cujo centro sempre fora ocupado pelas mulheres. Compreensivelmente, tais transformações forneceram material para inúmeras pesquisas a respeito das relações de gênero.

No caso do Brasil, segundo Gobbi (1999), os estudos sobre essa temática emergiram ainda na década de 1970, momento em que as lutas pelos direitos das mulheres somavam-se aos movimentos pela democracia. Os estudos então produzidos caracterizavam-se pela análise teórica e militância política em oposição aos discursos que desconsideravam as mulheres - e as crianças como sujeitos sociais. Por isso, o conceito de gênero passa a estar cada vez mais presente nos estudos que procuram diferenciar entre o biológico e o cultural no comportamento feminino e masculino (GOBBI, 1999).

Portanto, já se somam mais de quatro décadas de estudos sobre as relações de gênero. No final da década de 1990, Gobbi (1999) realizou pesquisa com crianças pequenas e verificou a presença entre suas representações dos tradicionais valores do espaço feminino e do espaço masculino. No primeiro caso, esse espaço está restrito ao ambiente doméstico e, no segundo caso, ao espaço público. No entanto, a autora encerra seu texto constatando que as crianças também demonstravam que a sociedade estaria passando por período de transição rumo a uma realidade mais igualitária. Diante disso, e pressupondo que ainda se vive esse período de transição, o objetivo dessa pesquisa foi investigar as representações de gênero diante das questões do que é ser homem 
e o que é ser mulher, entre alunos de escola pública, dos anos iniciais do ensino fundamental II.

\section{GÊNERO E ESCOLA}

A relação problemática entre os gêneros e escola moderna começou simultaneamente ao processo de escolarização que se intensificou a partir do final do século XIX. No início, por exemplo, era bastante comum a separação de meninos e meninas, mesmo quando frequentavam o mesmo espaço escolar. Ao longo do século XX, a prática da coeducação de meninos e meninas tornouse mais comum, mesmo que não tenha sido fundamentalmente em razão da igualdade entre os gêneros, mas sim em razão da economia que esta decisão acarretava aos cofres públicos (ALMEIDA, 2007). Portanto, "[...] o simples fato de estudarem nas mesmas escolas e classes, conteúdos e disciplinas similares, não garante para as meninas e moças as mesmas oportunidades sociais e no mundo do trabalho [...]" (ALMEIDA, 2015, p. 66). Por isso se concorda com Delamont (2012), quando ela afirma que as questões de gênero, estando ainda presentes nos sistemas de educação, estimulam a reflexão sobre como as crenças sobre gênero influenciam o cotidiano nas escolas e como a escola afeta as representações de gênero.

Enquanto as meninas ainda são educadas para maternidade e para o espaço privado, por meio da renúncia de seus desejos pessoais, os meninos são educados para exercer o poder e obter sucesso no espaço público, o que implica valorizar suas conquistas e reprimir seus afetos (GUTIÉRREZ, 2015). Considerando que a construção das identidades de gênero é uma construção coletiva, pode-se afirmar que a educação formal tem um papel privilegiado de socialização e de interação entre os iguais e com os adultos (MENÉNDEZ, 2005).

As interações sociais que ocorrem no interior da escola produzem e reproduzem símbolos e normas que fazem parte das representações de gênero que devem ser analisadas. Pensar sobre isso se faz necessário pois, grande parte delas perpetua preconceitos e estereótipos que causam situações conflituosas e negativas entre meninos e meninas (COSTA et al., 2009). A assimetria social entre homens e mulheres é consequência de uma estrutura de poder na qual prevalecem os valores masculinos. Valores estes que determinam os usos do 
corpo, modelam as relações afetivas e constituem códigos morais (MARTINS; TAQUETTE, 2012). Dias et al. (2015), estudando o caso de alunos e alunas de uma escola pública, concluíram que "[...] alguns entrevistados ainda estão presos a um padrão binário de gênero, acreditam que "homens" e "mulheres" possuem características próprias, congênitas, inatas, orgânicas, puras, e que há uma estabilidade interna desses termos" (p. 13).

Assim, considerando a importância do tema para a sociedade e para a escola, é sempre importante estudar as transformações pelas quais passam as relações de gênero no ambiente escolar. Stromquist (2007), analisando a produção acadêmica de vários países a respeito das relações de gênero nas escolas, concluiu que as escolas, independentemente do lugar, criam noções muito distintas daquilo que significa ser homem ou mulher. Para esse autor, inclusive, essa tendência se intensifica ao longo da vida escolar.

Como dito anteriormente, Gobbi (1999), estudando o caso de crianças pequenas, concluiu que as desigualdades de gênero ainda permaneciam, mas havia indícios que se caminhava para uma situação menos desigual. Mais de dez anos depois, Martins e Taquette (2012) realizaram investigação com adolescentes e chegaram à conclusão semelhante quando afirmam que "[...] não obstante a permanência da sobrecarga da mulher no espaço privado, a independência e a atuação profissional almejadas pelas entrevistadas indicam a incorporação de valores relacionais mais simétricos" (MARTINS; TAQUETTE, 2012, p. 41). A questão, portanto, permanece inquietante.

\section{METODOLOGIA}

Essa pesquisa, quanto à abordagem, caracteriza-se como qualitativa, pois objetiva "[...] o aprofundamento da compreensão de um grupo social [...]" (GERHARDT; SILVEIRA, 2009, p. 31). Nessa pesquisa, trata-se de meninos e meninas de uma escola pública. Em relação aos seus objetivos, esse estudo é exploratório e descritivo, pois intenta tornar mais evidente a questão escolhida, descrevendo o fenômeno estudado (GERHARDT; SILVEIRA, 2009), que nesse estudo são as representações de gênero. Portanto a pesquisa éfundamentalmente interpretativa, pois intenta compreender, pelo menos em parte, um processo social complexo e multifacetado (BHATTACHERJEE, 2012). Participaram deste 
estudo 226 estudantes de uma escola pública do município de Londrina-PR. Eram 126 meninos e 100 meninas, entre 10 e 11 anos, todos alunos de turmas sexto ano. Segundo Bhattacherjee (2012), a pesquisa interpretativa permite a utilização tanto da linguagem verbal quanto da não verbal. Por isso a opção pelo uso do desenho como fonte de informações a respeito das representações de gênero.

Pressupondo que os desenhos refletem o conhecimento que a criança tem do mundo, pode-se compreender, a partir deles, seus pensamentos e emoções. $O$ desenho, no entanto, não é fruto espontâneo de uma imaginação absolutamente livre, pelo contrário "[...] expressa os sentimentos do autor e o modo como a realidade é por este apropriada" (NATIVIDADE; COUTINHO; ZANELLA, 2008, p. 12). O desenho é forma simbólica que expressa representações que constituem a cultura. Essas formas simbólicas são utilizadas pelos indivíduos para se comunicar e partilhar experiências, concepções e crenças (THOMPSON, 1995). Porém, compreender um desenho não é simples, pois as imagens não falam por si mesmas, é necessário interpretá-las (NATIVIDADE; COUTINHO; ZANELLA, 2008). Costa et al. (2009) consideram os desenhos infantis como fontes documentais que têm um determinado papel cultual, portanto passíveis de interpretação. Assim, consideram os desenhos como instrumentos importantes que retratam as relações de gênero que existem na sociedade.

No início da pesquisa, os alunos foram avisados de que à atividade não seria atribuída nota alguma, para que eles não se preocupassem em responder corretamente ou agradar ao pesquisador. Também não foi necessário que os alunos se identificassem, o que garantiu anonimato e maior liberdade para os alunos expressarem seus pensamentos e sentimento. Após os esclarecimentos iniciais, foram distribuídas folhas de papel em branco que deveriam ser divididas em quatro partes. Os alunos identificaram na folha apenas duas informações, se eram meninos ou meninas e a idade no momento da aplicação da pesquisa. Nas duas partes superiores, os alunos deveriam responder as questões por escrito e, nos espaços inferiores, por meio de desenhos. A opção pelos dois tipos de respostas deve-se ao fato da necessidade, segundo Natividade, Coutinho e Zanella (2008), de complementar-se a análise de desenhos de crianças com outras fontes de informação. As questões que deveriam ser respondidas foram: "O que é ser homem?" e "O que é ser mulher?". 


\section{ANÁLISE DOS RESULTADOS}

A seguir são apresentados alguns exemplos de respostas fornecidas pelos alunos às questões propostas, representativos do conjunto de instrumentos recolhidos durante a aplicação da atividade.

Do total de alunos, 45 apresentaram a força - tanto física, quanto moral - como uma das características que distingue homens e mulheres. Meninos e meninas representaram os homens como fortes e as mulheres como fracas ou delicadas. Observando a Figura 1 e as respostas escritas (de dois alunos diferentes), podese perceber essas ideias claramente representadas.

Figura 1 - Força masculina e fragilidade feminina

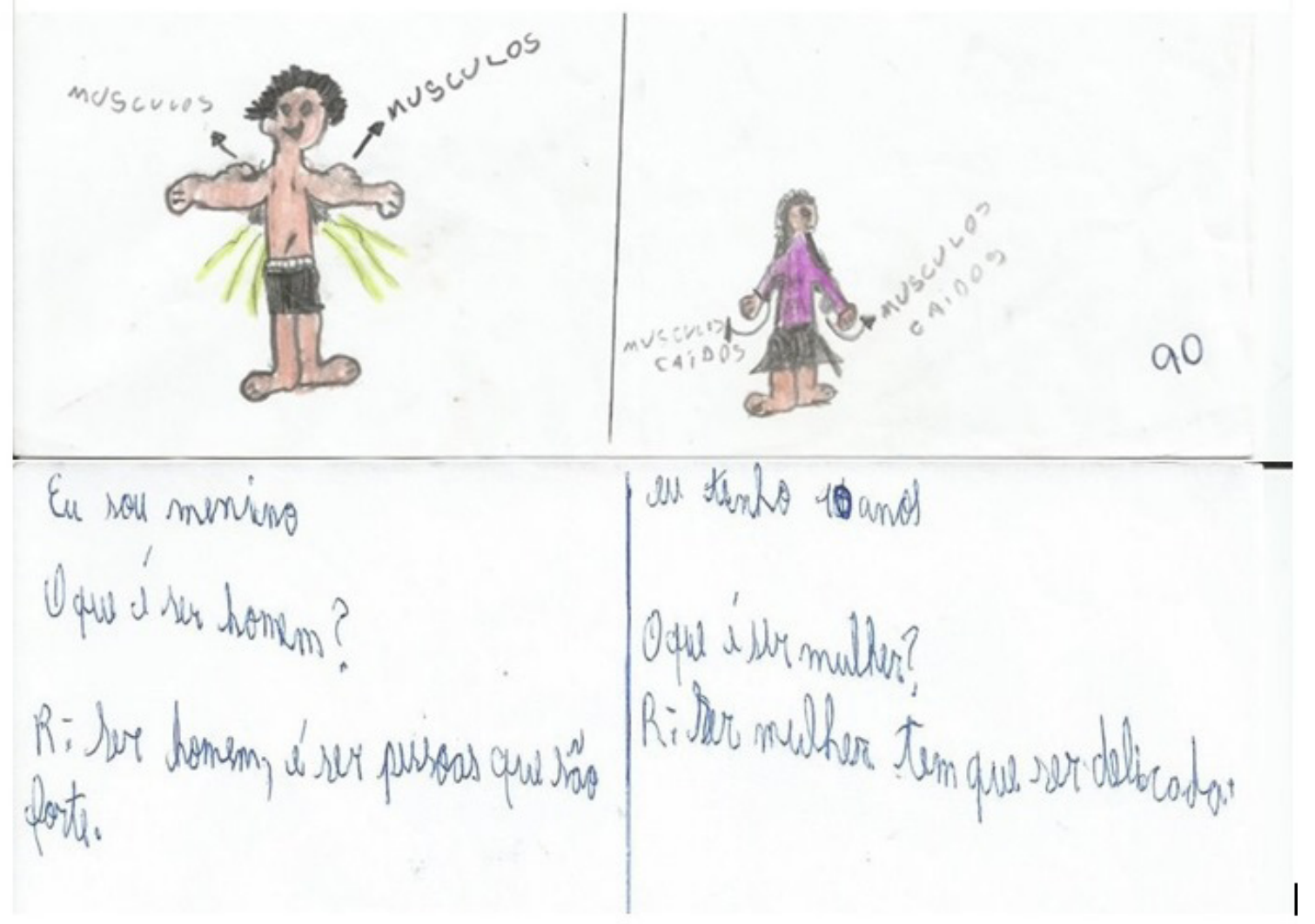

Fonte: Dados da pesquisa.

Vianna e Finco (2009), comentando a construção de papéis diferentes para meninos e meninas, afirmam que "[...] se, por um lado, é possível observar o controle da agressividade na menina, o menino sofre processo semelhante, mas em outra direção: nele são bloqueadas expressões de sentimentos como ternura, sensibilidade e carinho" (p. 272-273). Por isso Gutiérrez (2015) afirma que, na construção da masculinidade, a força e a violência são elementos centrais por meio dos quais os meninos afirmam sua masculinidade expressam desprezo por aqueles que socialmente encontram-se em posição inferior, como as mulheres. 
Resultados semelhantes foram encontrados em outras pesquisas. Costa et al. (2012), estudando as representações infantis de gênero e da sexualidade a partir de desenhos, apresentam a força física como uma das características masculinas destacadas pelas crianças. Muito semelhante, portanto, à opinião do médico do século XIX, citada por Ribeiro (1996), o que demonstra a durabilidade desses valores sociais.

Em 56 desenhos, foi possível perceber a ideia de que o espaço destinado aos homens é o público e, às mulheres, o privado. A representação de homens trabalhando fora para sustentar a família e a casa e de mulheres cuidando das crianças e realizando serviços domésticos foi igualmente comum nos desenhos e nas respostas escritas, como no exemplo da Figura 2.

Figura 2 - Homens trabalham fora, mulheres ficam em casa

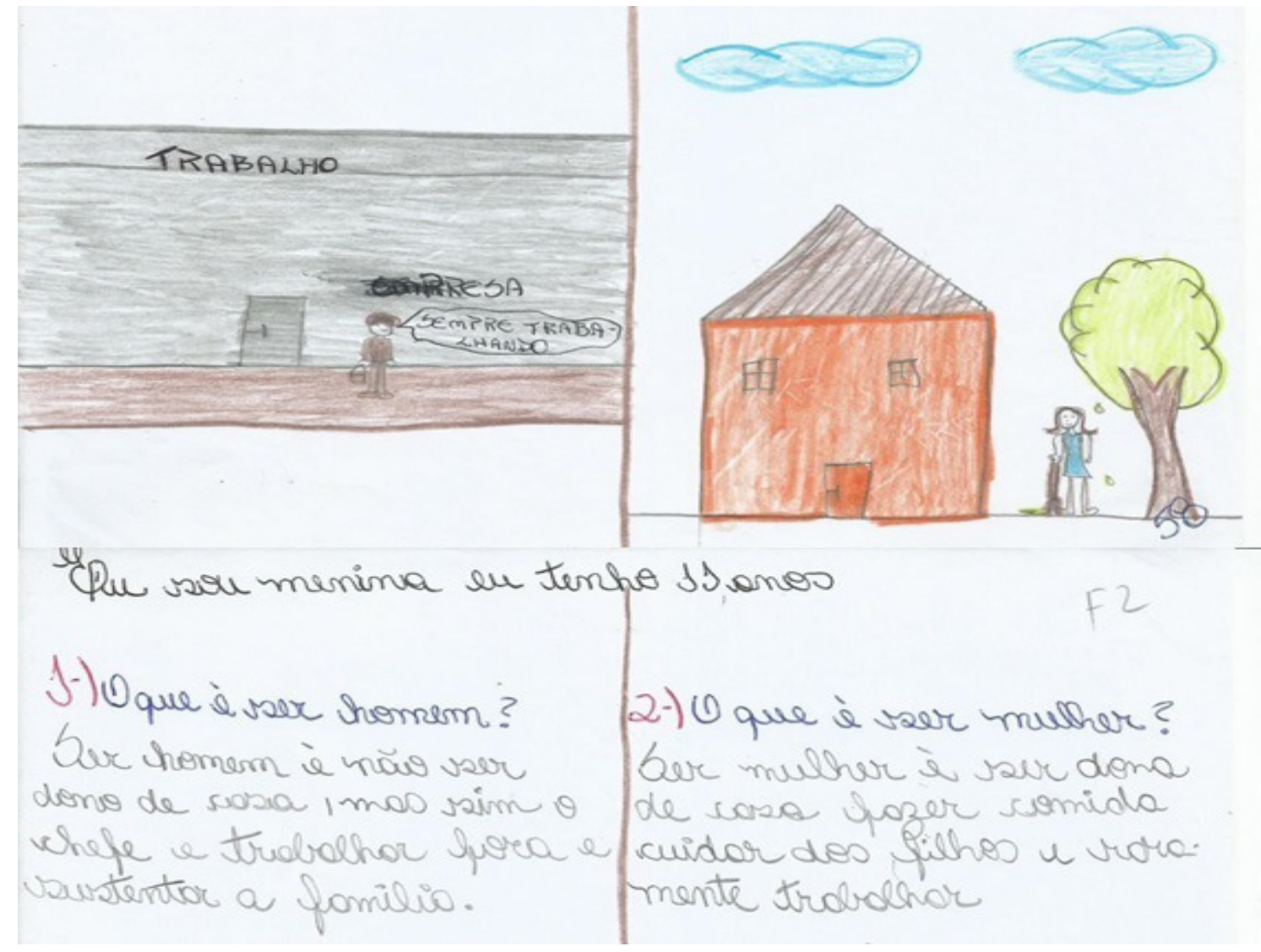

Fonte: Dados da pesquisa.

Encontraram-se 71 desenhos representando mulheres varrendo, lavando louça ou cuidando dos filhos, em oposição, os homens aparecem em situações fora de casa ou em seus empregos. Cuidar da casa e dos filhos parece ser encarado como destino ou dom das mulheres. Por outro lado, houve total ausência de representações de homens com seus filhos. Natividade, Coutinho e Zanella (2008), estudando desenhos de crianças, concluíram que "[...] os desenhos produzidos pelas crianças sugerem que elas ainda estão vinculadas ao discurso 
tradicional, em que as atividades domésticas são prioritariamente relacionadas ao papel feminino" (NATIVIDADE; COUTINHO; ZANELLA, 2008, p. 14). Mesmo considerando que muito provavelmente grande parte das mães desses alunos pesquisados trabalhe fora, tem-se de admitir que as mulheres "[...] estando em suas casas, cozinham para seus maridos e filhos. Nesse ponto, poder-se-ia pensar na confirmação das afirmações feitas de que o espaço doméstico seja de uso predominantemente feminino [...]" (GOBBI, 1999, p.152).

Outra representação frequente, 23 do total, nas produções das crianças diz respeito à ideia de que os homens sofrem menos que as mulheres, ou melhor, que as mulheres naturalmente destinam-se ao sofrimento. Seja porque têm filhos e têm de criá-los, seja porque fazem todo o trabalho de casa. Também houve referências à violência física que as mulheres sofrem de seus maridos, mas poucas, apenas 2. Por outro lado, em 33 desenhos, os homens foram apresentados em situações de lazer: tomando cerveja, jogando ou assistindo ao futebol, sentados ou dormindo. A Figura 3 representa esse tipo de resposta.

Figura 3 - Homens são folgados e as mulheres trabalhadeiras

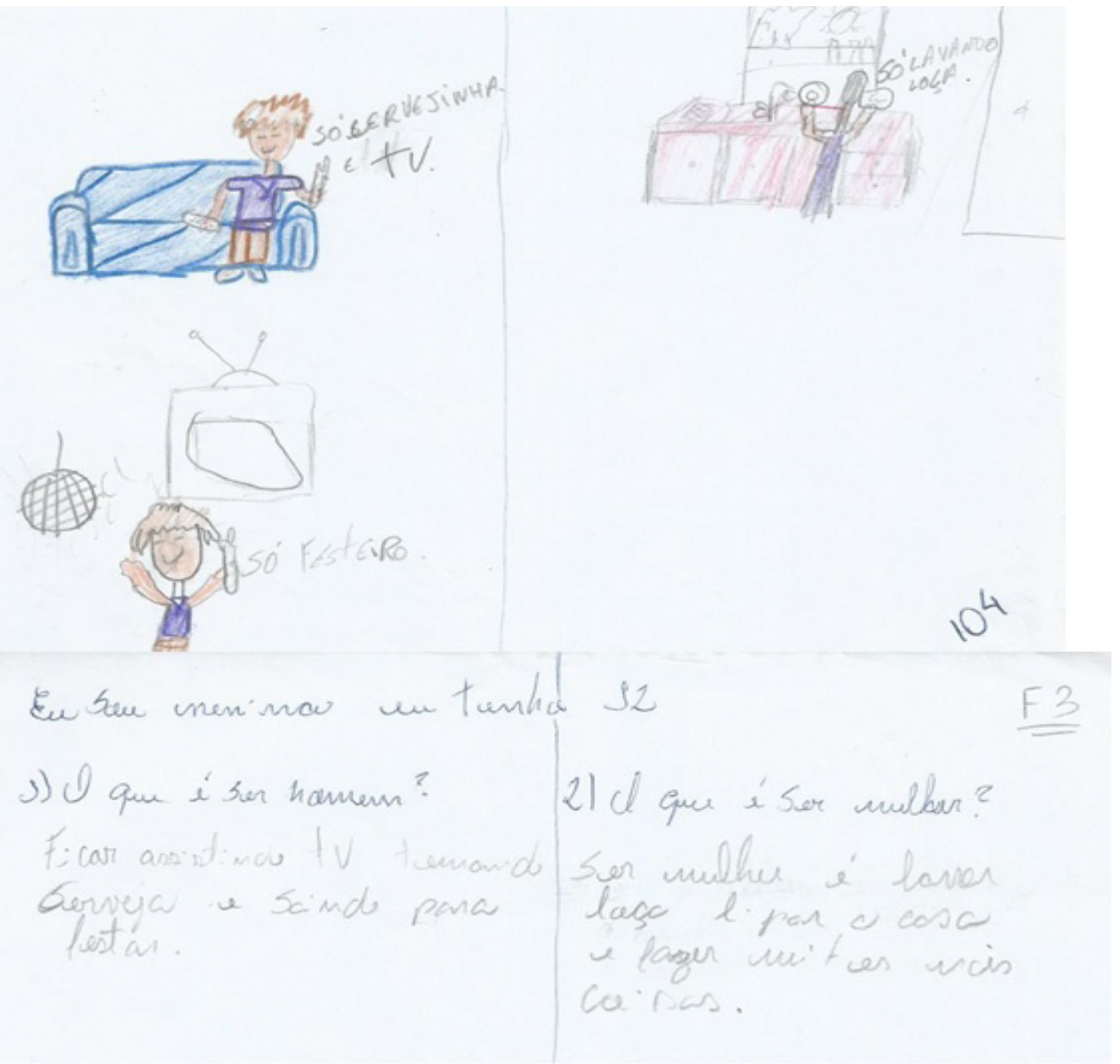

Fonte: Dados da pesquisa. 
Na pesquisa realizada por Costa et al. (2012) também encontramos essa mesma oposição. Em um dos casos exemplificados pelos autores, há um homem sentado, lendo jornal e, ao seu lado, uma mulher em pé com um uma vassoura; ela pede ajuda e ele diz que não. Em 83 desenhos, no entanto, surgiu a representação do homem como trabalhador e honesto, sustento do lar. Simultaneamente, as mulheres apareceram como consumistas, fúteis e vaidosas. Na Figura 4 (de dois alunos diferentes), pode-se observar essa oposição, que é uma espécie de inversão da representação contida na figura anterior.

Figura 4 - Homens ganham dinheiro e mulheres gastam

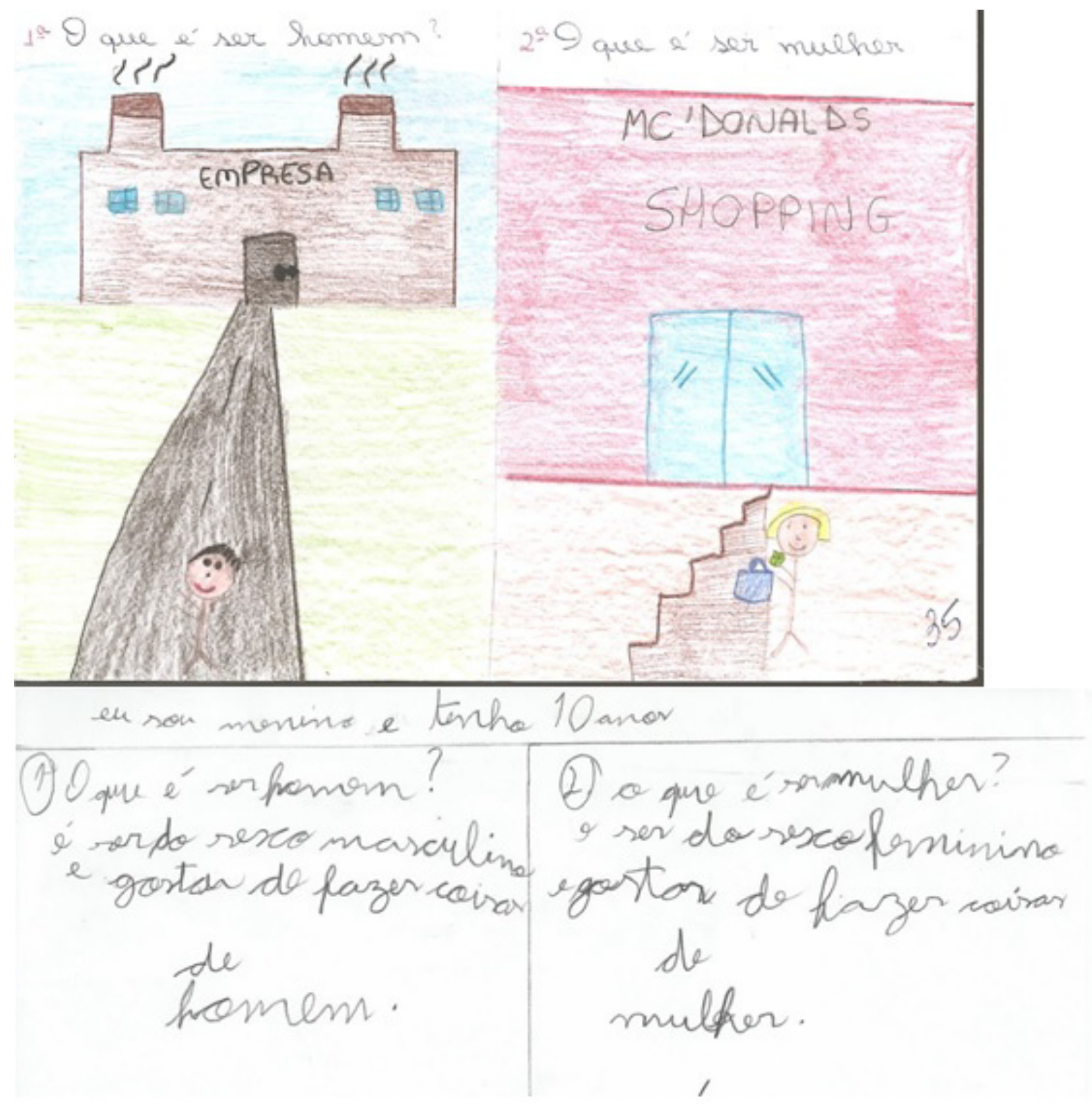

Fonte: Dados da pesquisa.

Ao mesmo tempo, as crianças demonstraram que a ideia de que existem coisas próprias para os homens fazerem e outras destinadas naturalmente para a mulheres ainda persiste. Para Vianna (2002), esse "[...] esquema binário [...] cristaliza concepções do que devem constituir atribuições masculinas e 
femininas e dificulta a percepção de outras maneiras de estabelecer as relações sociais" (p. 93). Essa dicotomia manifesta-se também em outra dimensão da relação entre homens e mulheres. A Figura 5 apresenta um exemplo da imagem do homem como macho conquistador, do qual se espera um comportamento ativo. Da mulher, pelo contrário, espera-se o recato; quando isso não ocorre, ela é socialmente desvalorizada.

Figura $\mathbf{5}$ - Diferentes expectativas

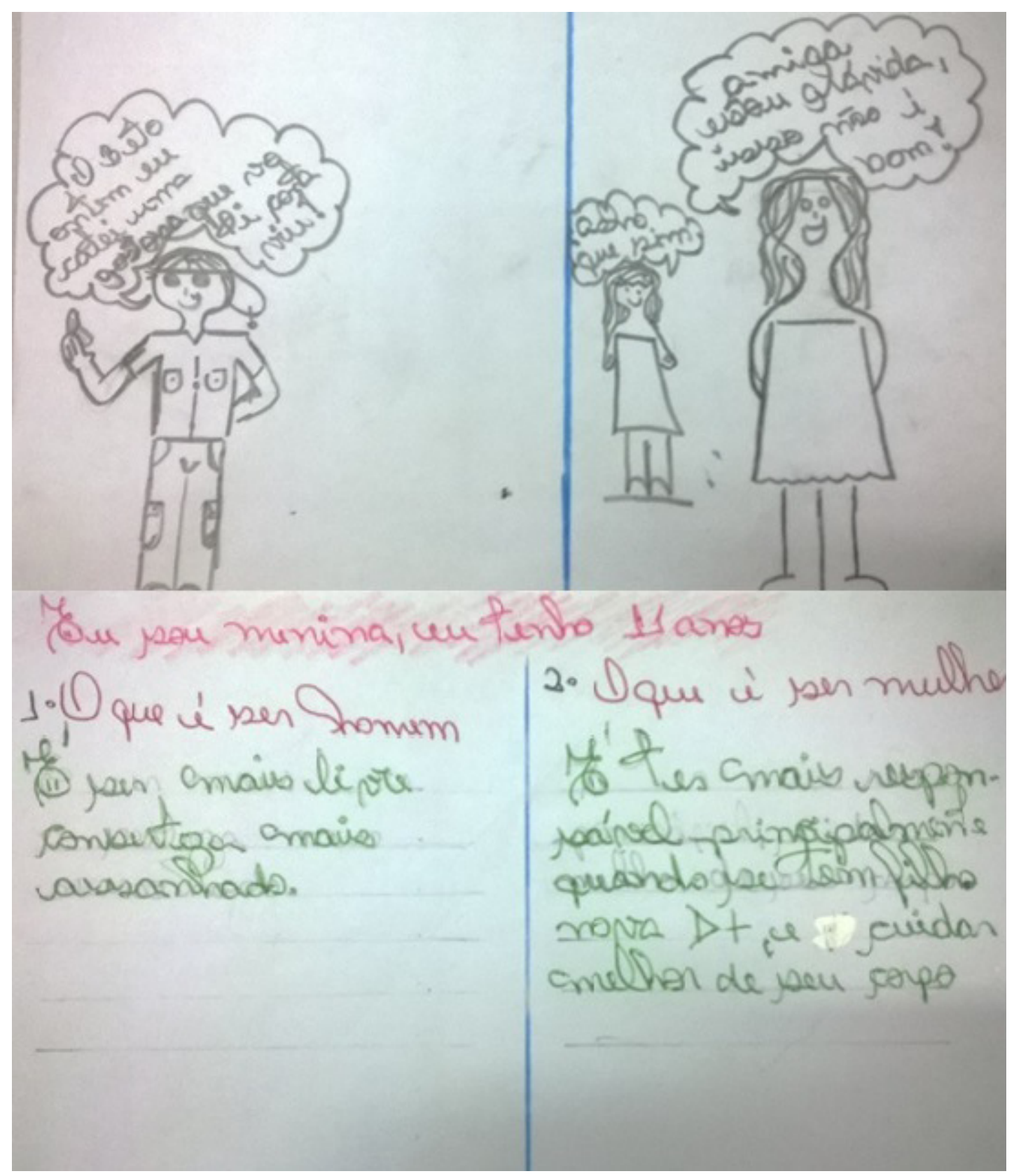

Fonte: Dados da pesquisa.

Essa representação do papel do homem está ligada à ideia de que a ele cabe mais liberdade quanto aos relacionamentos. No exemplo da Figura 5, isso fica evidente, tanto no desenho quanto na escrita: à mulher cabe a responsabilidade de criar os filhos. Por outro lado, assim como Gobbi (1999) e Martins e Taquette (2012), também foram encontradas evidências de que há alguma mudança em 
andamento em direção a uma situação mais igualitária. Na Figura 6, há um exemplo desse tipo de ideia.

Figura 6 - Homem e mulher: nuances e contradições
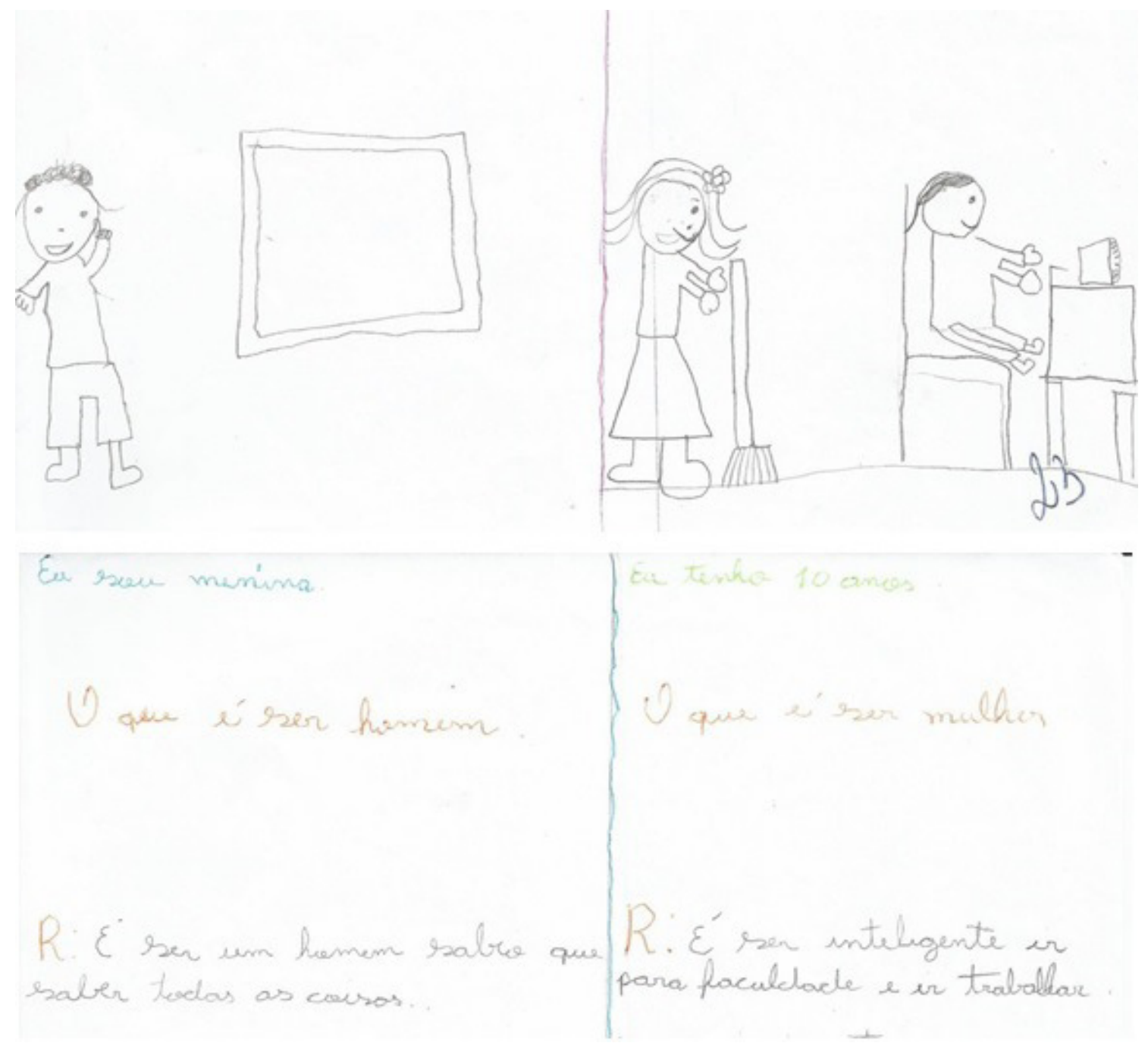

Fonte: Dados da pesquisa.

Na Figura 6, encontra-se uma nova perspectiva da relação dos gêneros que afirma a importância do estudo e da inteligência para homens e mulheres. Especialmente quando afirma que ser mulher é "ir" para a faculdade e trabalhar, afastando-a dos trabalhos domésticos. No entanto, a criança demonstra uma contradição quando coloca a vassoura nas mãos da mulher. Isso é representativo desse momento de transição proposto por Gobbi (1999) e Martins e Taquette (2012). Considerando que as representações dos alunos fazem parte daquelas que estão presentes na família, na escola e na sociedade, pode-se concluir que mudanças estão ocorrendo nesses espaços. Para Brito (2015), essa transformação "[...] mostra que outros olhares começam a ser construídos e performados na educação de meninos e meninas e, deste modo, rupturas mais significativas podem estar mais próximas de se efetivarem de forma mais incisiva nos espaços escolares" (p. 87). Há esperança, portanto. 


\section{CONSIDERAÇÕES FINAIS}

Apesar de se entender que se está passando por um momento de transição acerca das relações e das representações de gêneros na, ainda assim se encontram nos desenhos de alunos, crianças ainda, a hegemonia masculina e a reprodução de estereótipos a respeito do universo feminino e masculino. Enquanto a questão de gênero, na sociedade e mais especificamente no universo escolar, for abordada e entendida a partir de valores patriarcais, como sendo a única maneira de entender o sistema social, estar-se-ão destinados a cair no reducionismo simplista da existência de uma única história possível a ser escrita e vivida. Com isso, permanecer-se-ão enclausurados a uma educação e a um ensino sem perspectivas de futuro mais justo. As representações dos alunos demonstram a urgência de mudanças nas relações de poder que permeiam e constituem a sociedade de modo mais amplo.

A pesquisa demonstrou que os alunos carregam forte a marca da cultura na qual vivem. As representações observadas revelaram uma série de dicotomias preconceituosas, mas também um fio de esperança. A antiga perspectiva, que compreende os homens como mais fortes do que as mulheres, ainda está presente, valor intimamente relacionado a outra dicotomia, o público e o privado. Aos homens caberia o espaço público justamente por serem mais fortes. Às frágeis e delicadas mulheres restaria o espaço do lar. Em consonância, ao homem é dada mais liberdade, aceitando seu comportamento como naturalmente mais arrojado. Nesse sentido, dos homens espera-se atrevimento na relação com as mulheres, mas, das mulheres, deseja-se o recato. Talvez por serem consideradas mais fracas que os homens. Fragilidade que parece manifestar-se também na ideia de que elas são mais consumistas do que os homens, sendo estes um dos estereótipos que compõe os valores da sociedade do espetáculo¹.

Os desenhos dos alunos são, portanto, um convite para educadores se questionar: até que ponto se deixará que valores morais preconceituosos sejam perpetuados em nas escolas? Até quando se ficará alheio a essas representações de gênero que estão no universo escolar e deixar que essa história continue a ser contada pelas futuras gerações? Pensa-se que, como educadores, tem-se muito trabalho pela frente em busca de outro futuro, outra educação e um mundo no qual seja possível falar em igualdade de gênero. 
ALMEIDA, J. S. de. A Construção da diferença de gênero nas escolas: aspectos históricos (São Paulo, séculos XIX e XX). Revista Eletrônica de Educação, v. 9, n. 1, 2015, p. 65-77. Disponível em: <http://www.reveduc.ufscar.br/index.php/reveduc/ article/viewFile/1039/379>. Acesso em: 28 jan. 2016.

ALMEIDA, J. S. de. Ler as letras: por que educar meninas e mulheres? Campinas, Autores Associados, 2007.

BHATTACHERJEE, A.. Social Science research: principles, methods, and practices. Tampa: University of South Florida, 2012.

BRASIL. Decreto-Lei 4244 de 9 de abril de 1942. Disponível em: <http://www2. camara.leg.br/legin/fed/declei/1940-1949/decreto-lei-4244-9-abril-1942-414155publicacaooriginal-1-pe.html>. Acesso em: 20 jan. 2016.

BRITO, L. T. Gênero no espaço escolar. Caderno Espaço Feminino, v. 28, n. 1, 2015, p. 72-89. Disponível em: < http://www.seer.ufu.br/index.php/neguem/article/view/ 29708/17213>. Acesso em: 3 fev. 2016.

COSTA, A. P. et al. Sexualidade, gênero e educação: novos olhares. In: Revista Iberoamericana de Estudos em Educação, v. 4, n. 1, 2009, p. 1-12. Disponível em: <http:// seer.fclar.unesp.br/iberoamericana/article/view/2691/2401>. Acesso em 26 jan. 2016.

COSTA, A. P. et al. Tamanho é documento? Uma análise da sexualidade, relações de gênero e formação docente através de desenhos infantis. Revista Ibero-Americana de Estudos em Educação, v. 7, n. 2, 2012, p. 133-152. Disponível em: <http://seer. fclar.unesp.br/iberoamericana/article/view/5715/4446>. Acesso em 20 jan. 2016.

DEBORD, G. A sociedade do espetáculo. São Paulo: Contraponto, 1967.

DELAMONT, S. Sex roles and the school. New York: Routledge, 2012.

DIAS, V. G. et al. Representações de gênero na escola: ensino e pesquisa sobre imagens do feminino no Instituto Federal do Rio de Janeiro. Anais do Seminário de Ciências Sociais e Educação Básica, n. 1, 2015. Disponível em: <http://cp2.g12.br/ ojs/index.php/cienciassociais/article/view/409/344>. Acesso em 4 fev. 2016.

GERHARDT, T. E.; SILVEIRA, D. T. Métodos de pesquisa. Porto Alegre: Editora da UFRGS, 2009.

GOBBI, M. Lápis vermelho é de mulherzinha: desenho infantil, relações de gênero e crianças pequenas. Revista Pro-Posições, v. 10, n. 28, mar., 1999, p. 139-156. Disponível em: <http://www.proposicoes.fe.unicamp.br/proposicoes/textos/28artigos-gobbim.pdf>. Acesso em: 27 jan. 2016.

DÍEZ GUTIÉRREZ, E. J. Códigos de masculinidade hegemónica em educación. Revista Iberoamericana de Educación, v. 68, 2015, p. 79-98. Disponível em: <http://www. rieoei.org/rie68a04.pdf>. Acesso em: 27 jan. 2015. 
HOBSBAWM, E. Era dos extremos. São Paulo: Cia das Letras, 1995.

MARTINS, M. T. S. de L.; TAQUETTE, S. R.. Relacionamento entre homens e mulheres nascidas pós movimento feminista. Revista Conhecimento e Diversidade, n. 7, jan./ jun., 2012, p. 29-42. Disponível em: <http://www.revistas.unilasalle.edu.br/ index. php/conhecimento_diversidade/article/view/621>. Acesso em 25 jan. 2016.

MENÉNDEZ, M. C. R. La construccion del género em los primeiros años de escuela: una mirada desde la perspectiva del professorado. Revista Iberoamericana de Educación, n. 35/1, 2005, p. 1-12. Disponível em: <http://www.rieoei.org/ deloslectores/902Rodriguez.pdf>. Acesso em: 27 jan. 2016.

NATIVIDADE, M. R. da; COUTINHO, M. C.; ZANELLA, A. V. Desenho na pesquisa com crianças: análise na perspectiva histórico-cultural. Revista Contextos Clínicos, v. 1, n., 1, jan./jun., 2008, p. 9-18. Disponível em: < http://pepsic.bvsalud.org/scielo. php? pid=S1983-34822008000100002\&script=sci_arttext $>$. Acesso em 25 jan. 2016.

RIBEIRO, A. I. M.. Algumas reflexões sobre a educação das mulheres no século XIX. Revista Nuances, v. 2, set., 1996, p. 26-31. Disponível em: <http://revista.fct.unesp. br/index.php/Nuances/article/viewFile/38/33 > . Acesso em: 25 jan. 2016.

STROMQUIST, N. P. The gender socialization process in schools: a cross-national compararison. Paris: Unesco, 2007. Disponível em: <http://unesdoc.unesco.org/ images/0015/001555/155587e.pdf>. Acesso em: 3 fev. 2016.

THOMPSON, J. B. Ideologia e cultura moderna: teoria social crítica na era dos meios de comunicação de massa. Petrópolis: Vozes, 1995.

VIANNA, C. P. O Sexo e o gênero da docência. Cadernos Pagu, v. 17, n. 18, 2002, p. 81-103. Disponível em: http://www.scielo.br/pdf/cpa/n17-18/n17a03.pdf>. Acesso em: 02 fev. 2016.

VIANNA, C.; FINCO, D. Meninas e meninos na educação infantil: uma questão gênero e poder. Cadernos Pagu, n. 33, jul./dez. 2009, p. 265 -283. Disponível em:

<http://www.scielo.br/scielo.php?pid=S010483332009000200010\&script $=$ sci_ arttext>. Acesso em 5 fev. 2014.

Artigo recebido em: 29/02/2016

Aprovado em: 19/07/2016

\section{Endereço para correspondência:}

Fabio Luiz Silva. Rua: Marselha, 591, Jardim Piza, Londrina, PR, CEP: 86041-120. E-mail: fls.londrina@yahoo.com.br 
Cyntia Simioni França. Rua: Marselha, 591, Jardim Piza, Londrina, PR, CEP: 86041120. E-mail: cyntiasimioni@yahoo.com.br

NOTAS

${ }^{1}$ Segundo Debord, "O mundo ao mesmo tempo presente e ausente que o espetáculo apresenta é o mundo da mercadoria dominando tudo o que é vivido". (1967, p. 29) Além disso, o espetáculo é o momento em que a mercadoria chega à ocupação total da vida social. Tudo isso é perfeitamente visível com relação à mercadoria, pois nada se vê senão ela: o mundo visível é o seu mundo. (1967, p.32). 